\section{International Scientific Journal Theoretical \& Applied Science}

p-ISSN: 2308-4944 (print) e-ISSN: 2409-0085 (online)

Year: $2017 \quad$ Issue: $03 \quad$ Volume: 47

Published: $30.03 .2017 \quad$ http://T-Science.org
E.S. Belyaev

Candidate of technical Sciences, associate professor of «Materials science, technology of materials and heat treatment of metals» Nizhny Novgorod State Technical University n.a. R.E. Alekseev

N. V. Makarov

Postgraduate student of the Department «Materials science, technology of materials and heat treatment of metals» Nizhny Novgorod State Technical University n.a.

R.E. Alekseev

M.A. Kravchenko

Master student of the Department «Materials science, technology of materials and heat treatment of metals» Nizhny Novgorod State Technical University n.a. R.E. Alekseev

\title{
FORMATION OF THE STRUCTURE AND PROPERTIES OF POWDER ROLLS BASED ON COPPER WITH NANO DIMENSIONAL DIAMOND FILLER
}

Abstract: This study considers the formation of the properties of a powder sheet material with a nano-sized diamond filler RUDDM 0-0.5 with the use of a copper metal sheath, depending on the operations of the technological process.

Key words: powder metallurgy, diamond-bearing rolling, porosity, shrinkage, ultimate strength, microhardness, microstructure.

Language: Russian

Citation: Belyaev ES, Makarov NV, Kravchenko MA (2017) FORMATION OF THE STRUCTURE AND PROPERTIES OF POWDER ROLLS BASED ON COPPER WITH NANO DIMENSIONAL DIAMOND FILLER. ISJ Theoretical \& Applied Science, 03 (47): 77-84.

Soi: http://s-o-i.org/1.1/TAS-03-47-17 Doi: crossef https://dx.doi.org/10.15863/TAS.2017.03.47.17

\section{ФОРМИРОВАНИЕ СТРУКТУРЫ И СВОЙСТВ ПОРОШКОВОГО ПРОКАТА НА ОСНОВЕ МЕДИ С НАНОАЛМАЗНЫМ НАПОЛНИТЕЛЕМ}

Аннотация: В настоящем исследовании рассмотрено формирование свойств порошкового листового материала с наноразмерным алмазным наполнителем марки RUDDM 0-0,5 с применением медной металлической связки в зависимости от операчий технологического процесса.

Ключевые слова: порошковая металлургия, алмазосодержащий прокат, пористость, усадка, предел прочности, микротвердость, микроструктура.

\section{Введение}

Порошковые алмазосодержащие микрометрическим тонколистовые материалы алмазным наполнителем широко применяются при абразивной обработке неметаллических материалов для нужд электронной промышленности [1-7].

Изготавливают такие материалы методом порошковой металлургии, технологический процесс состоит из следующих основных этапов: смешивание шихты; холодная прокатка шихты в пористую ленту; спекание; многоцикловая механо-термическая обработка (МТO); термофиксация. МТО представляет собой уплотняющую прокатку в сочетании с последующим отжигом. Формирование

свойств тонколистовых алмазосодержащих материалов с микрометрическим алмазным наполнителем происходит в процессе многоцикловой МТО, что подробно рассмотрено в работах [1-7].

В работе [8] рассмотрено влияние микро- и нанометрического алмазного наполнителя на механические свойства порошкового проката. Показано, что уменьшение размера алмазного наполнителя снижает механические свойства, что связано с различным характером распределения по металлической матрице микро- и 
нанометрического алмазного наполнителя. Расчетным методом установлена максимально допустимая условная концентрация $K$ наноалмазного наполнителя марки RUDDM 0-0,5 из условия образования металлической связи между частицами связки при спекании и промежуточных отжигах.

Получение алмазосодержащих материалов с микро- и нанометрическим алмазным наполнителем выполнено по схожей технологической схеме, за исключением операции смешивания шихты. При смешивании шихты с микрометрическим алмазным наполнителем применяется перемешивание в баночном смесителе, а при использовании нанометрического наполнителя смешивание проводили в шаровой мельнице в каскадноводопадном режиме.

В настоящем исследовании рассмотрено формирование свойств порошкового листового материала с наноразмерным алмазным наполнителем марки RUDDM 0-0,5 с применением медной металлической связки.

\section{Материалы и оборудование}

Порошковый прокат с наноразмерным алмазным наполнителем изготавливался методом порошковой металлургии (прокатка + спекание + МТО). Прокат имел различную концентрацию нанолмазного наполнителя - 0,8 масс. \%, 2,4 масс. $\%, 4,2$ масс. \%, что соответствует условной концентрации $K: 8 \% ; 24 \%$ и $40 \%$.

Двухкомпонентная шихта сформирована из порошка меди ПМС-1 ГОСТ 4960-2009 и порошка поликристаллических алмазов RDDM O0,5 с различной, указанной выше концентрацией.

Порошок поликристаллических алмазов $R D D M \quad 0-0,5 \quad$ представляет собой легко разрушаемые крупные конгломераты, поэтому смешивание шихты выполнено в шаровой мельнице для разрушения исходных конгломератов и равномерного распределения наноалмазного наполнителя по объему шихты. Время смешивания 10 часов в каскадноводопадном режиме. Этого времени оказалось достаточно для равномерного распределения наполнителя по объему шихты.

После смешивания в шихту добавлялся пластификатор - этиловый спирт в количестве 3\% от массы для увеличения формуемости смеси.

Прокатка шихты в ленту осуществлялась в прокатном стане дуо с горизонтально расположенными валками. Образцы после прокатки имели пористость П=35\% и толщину 1800 мкм.

Далее прокатанная лента нарезалась на полосы небольшой длины, которые спекались в остроосушенном водороде при температуре 850 ${ }^{\circ} \mathrm{C}$ в течении 120 минут. Спекание проводилось для упрочнения образцов, т.е для образования металлической связи между частицами порошка меди.

Спеченный прокат подвергался нескольким циклам МТО для уплотнения и увеличения физико-механических характеристик.

Измерение удельной поверхности шихты выполнено с помощью прибора ПСХ-10а, измерение физико-механичесих свойств выполнено с помощью универсальной испытательной машины Inspekt и микротвердомера ПМТ-3, просмотр микроструктуры выполнен с помощью цифрового микроскопа Keyence $V H X-1000$ и растрового электронного микроскопа $V E G A 3$ TESCAN.

\section{Полученные результаты и обсуждение \\ Влияние смешивания, совмещенного с помолом, на удельную поверхность полученных порошковых смесей.}

В процессе обработки шихты в шаровой мельнице происходит изменение формы частиц меди с разветвленной (рисунок 1а) на более округлую (рисунок 2б), что связано с деформацией металлических частиц мелющими телами. Удельная поверхность порошка меди до смешивания, совмещенного с размолом, составляет $1345 \mathrm{~cm}^{2} /$ г. В процессе смешивания алмазный наполнитель равномерно распределился по поверхности частиц порошка меди, что иллюстрирует рисунок 2.

Удельная поверхность шихты с различным содержанием алмазного наполнителя приведена на рисунке 3. После смешивания по мере роста массового содержания алмазного наполнителя величина удельной поверхности смеси также возрастает. Алмазный наполнитель, распределяясь по поверхности частиц меди, увеличивает удельную поверхность.

Очевидно, что в процессе смешивания, совмещенного с помолом, уменьшение удельной поверхности порошка меди, связанное с его деформированием, компенсируется наличием на поверхности частиц алмазного наполнителя. 


\begin{tabular}{l|lrl|l|ll} 
& ISRA (India) & $=\mathbf{1 . 3 4 4}$ & SIS (USA) & $=\mathbf{0 . 9 1 2}$ & ICV (Poland) & $=\mathbf{6 . 6 3 0}$ \\
Impact Factor: & ISI (Dubai, UAE) $=\mathbf{0 . 8 2 9}$ & PVHIL (Russia) $=\mathbf{0 . 2 3 4}$ & PIF (India) & $=\mathbf{1 . 9 4 0}$ \\
& GIF (Australia) & $\mathbf{0 . 5 6 4}$ & ESJI (KZ) & $=\mathbf{1 . 0 4 2}$ & IBI (India) & $\mathbf{4 . 2 6 0}$
\end{tabular}
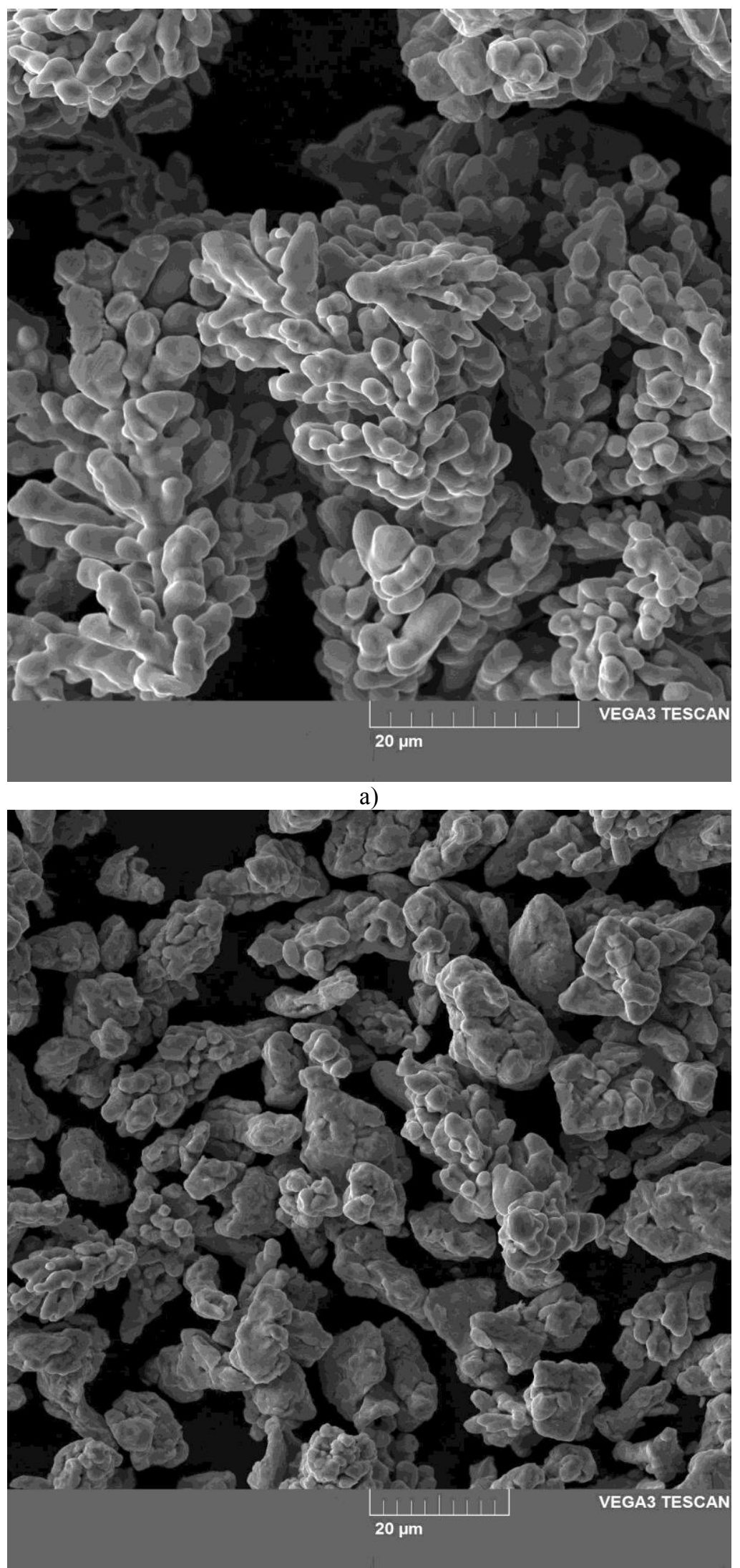

б)

Рисунок 1 - Морфология поверхности частиц порошка меди (а) до смешивания и после смешивания (б) с алмазным наполнителем в концентрации 0,8 масс. \%. 


\begin{tabular}{|c|c|c|c|c|c|c|}
\hline Impact Factor: & $\begin{array}{l}\text { ISRA (India) } \\
\text { ISI (Dubai, UAE } \\
\text { GIF (Australia) } \\
\text { JIF }\end{array}$ & $\begin{array}{r}=1.344 \\
=0.829 \\
=0.564 \\
=1.500\end{array}$ & $\begin{array}{l}\text { SIS (USA) } \\
\text { PИHЦ (Russia) } \\
\text { ESJI (KZ) } \\
\text { SJIF (Morocco) }\end{array}$ & $\begin{array}{l}=0.912 \\
=0.234 \\
=1.042 \\
=\mathbf{2 . 0 3 1}\end{array}$ & $\begin{array}{l}\text { ICV (Poland) } \\
\text { PIF (India) } \\
\text { IBI (India) }\end{array}$ & $\begin{array}{l}=6.630 \\
=1.940 \\
=4.260\end{array}$ \\
\hline
\end{tabular}

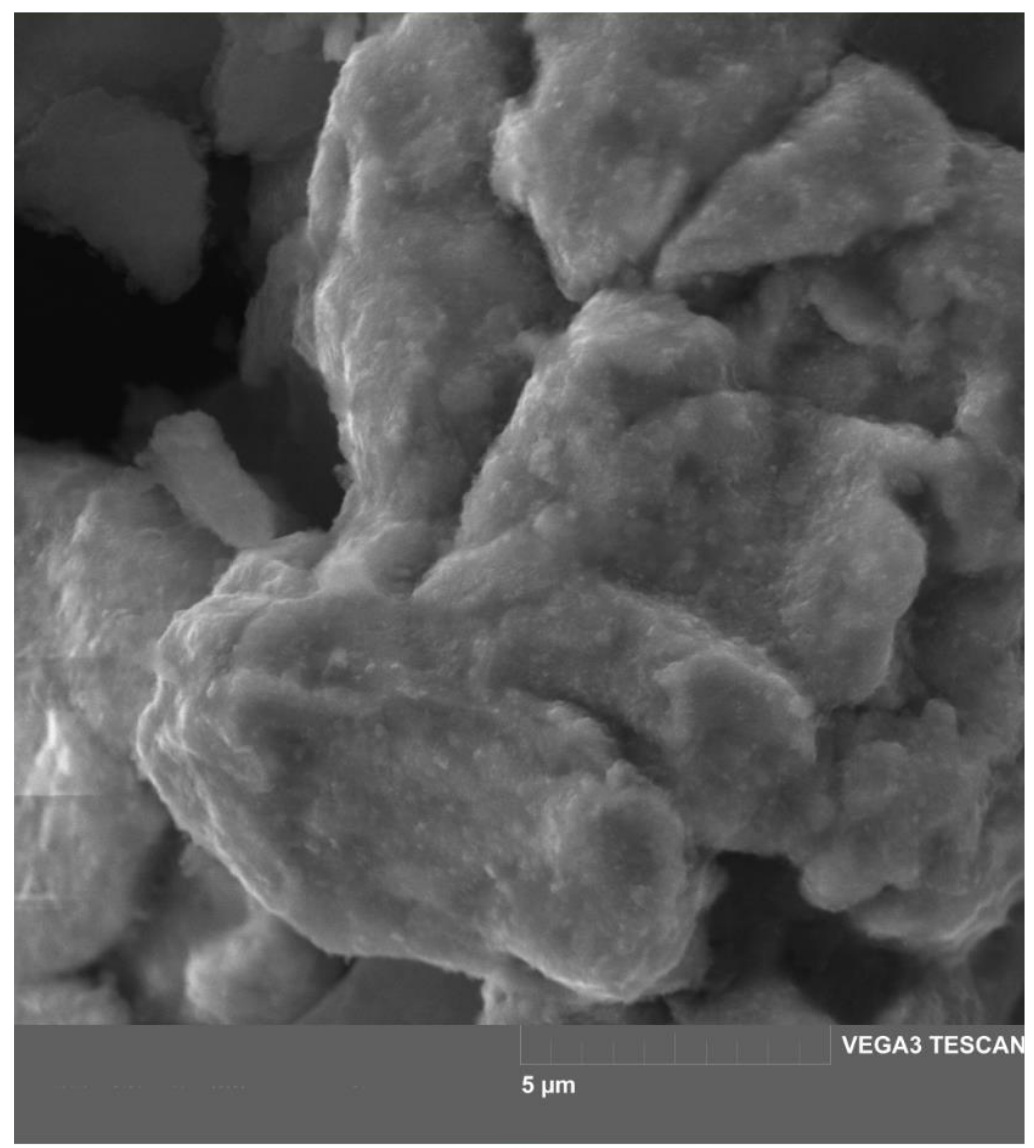

Рисунок 2 - Морфология поверхности частиц порошка меди с алмазным наполнителем в концентрации 4,2 масс. \%.

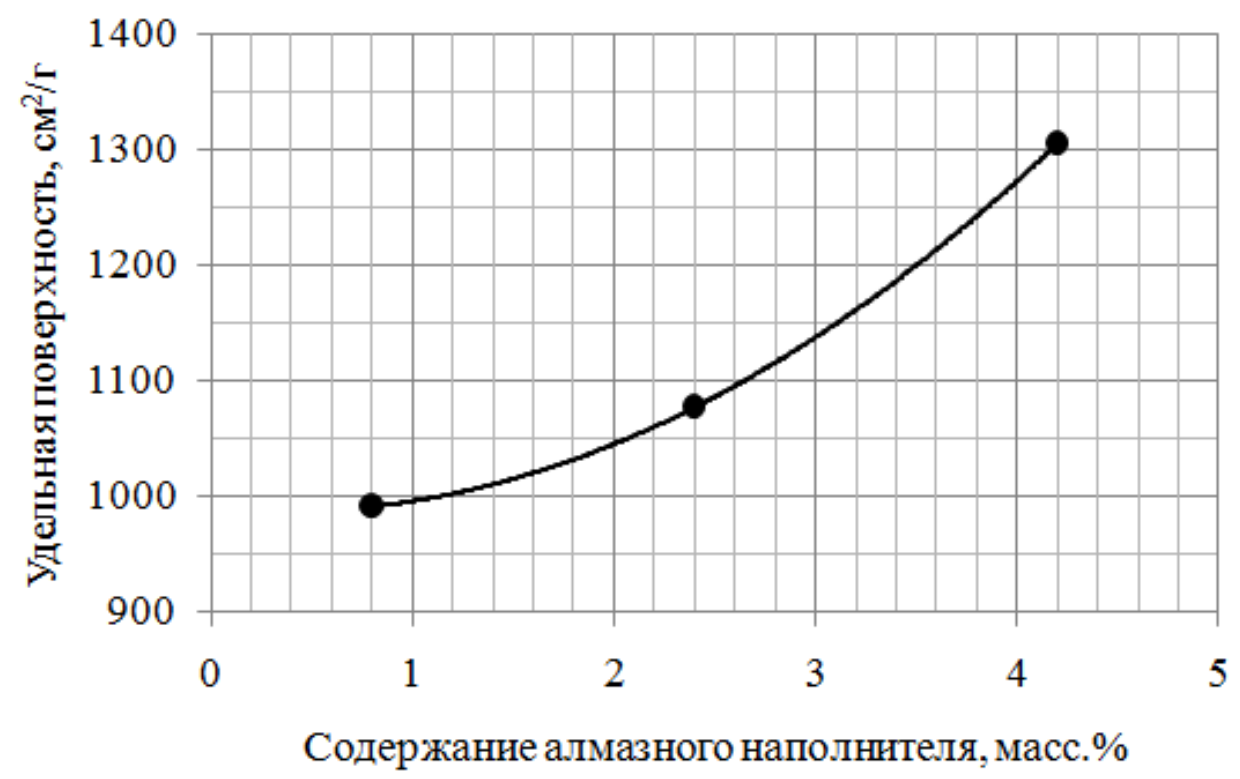

Рисунок 3 - Зависимость значения удельной поверхности от массового содержания алмазного наполнителя после смешивания в шаровой мельнице.

Пористость и усадка после спекания и многоцикловой МТО
Как указано выше, пористость после холодной прокатки шихты в ленту составляет
ISPC Technological breakthrough in science, Philadelphia, USA 


\begin{tabular}{|c|c|c|c|c|c|c|}
\hline Impact Factor: & $\begin{array}{l}\text { ISRA (India) } \\
\text { ISI (Dubai, UAE } \\
\text { GIF (Australia) } \\
\text { JIF }\end{array}$ & $\begin{array}{l}=1.344 \\
=0.829 \\
=0.564 \\
=1.500\end{array}$ & $\begin{array}{l}\text { SIS (USA) } \\
\text { PИНЦ (Russia) } \\
\text { ESJI (KZ) } \\
\text { SJIF (Morocco) }\end{array}$ & $\begin{array}{l}=0.912 \\
=0.234 \\
=1.042 \\
=2.031\end{array}$ & $\begin{array}{l}\text { ICV (Poland) } \\
\text { PIF (India) } \\
\text { IBI (India) }\end{array}$ & $\begin{array}{l}=6.630 \\
=1.940 \\
=4.260\end{array}$ \\
\hline
\end{tabular}

35\%. Минимальное значение пористости достигается после спекания и двух циклов МТО и составляет $\Pi=6-15 \%$ в зависимости от содержания алмазного наполнителя. Изменение пористости по операциям представлено рисунке 4.

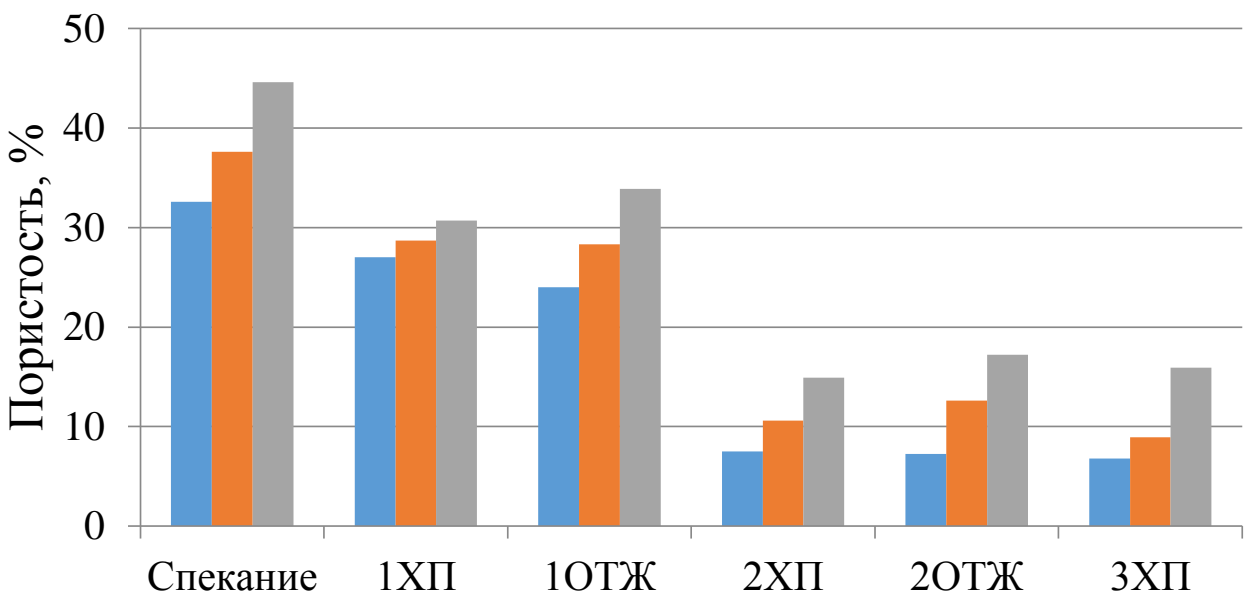

0,8 масс. $\%$

2,4 мacc. $\%$

4,2 мacc. $\%$

Рисунок 4 - Диаграмма изменения пористости по операциям технологического процесса

В процессе спекания и после промежуточных отжигов полученные материалы в зависимости от содержания алмазного наполнителя имеют усадку или рост. Прокат с содержанием $\quad 0,8 \%$ алмазного наполнителя проявляет усадку после спекания и первого промежуточного отжига и незначительный рост после второго отжига. При концентрациях 2,4\% и $4,2 \%$ наблюдается рост размеров после термической обработки. Причем при концентрации 2,4 масс. \% значения роста размеров уменьшаются с каждой последующей термической обработкой, а при концентрации 4,2 масс. \% рост размеров увеличивается.

В процессе спекания окислы на поверхности частиц меди довосстанавливаются с выделением водяного пара. Большая удельная поверхность алмазного наполнителя может адсорбировать некоторое количество газов из воздуха и паров этилового спирта при прокатке [9].

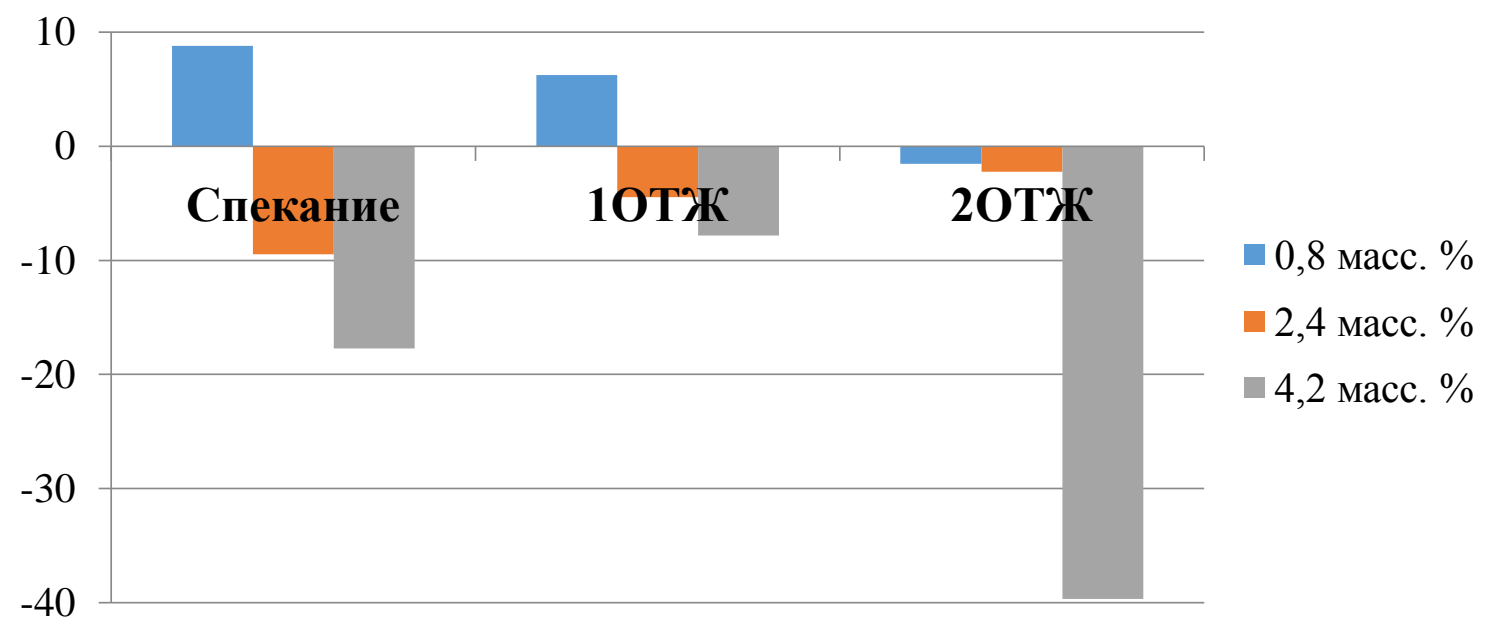

Рисунок 5 - Диаграмма изменения усадки после термической обработки проката

\begin{abstract}
При термической обработке адсорбированные газы будут покидать поверхность алмазного наполнителя, что в комплексе с процессами восстановления частиц меди будет повышать давление внутри материала
\end{abstract}

и приведет к росту размеров после термической обработки.

Механические свойства после спекания и многоцикловой МТО

Изменение предела прочности на растяжение проката по операциям 


\begin{tabular}{|c|c|c|c|c|c|c|}
\hline Impact Factor: & $\begin{array}{l}\text { ISRA (India) } \\
\text { ISI (Dubai, UAB } \\
\text { GIF (Australia) } \\
\text { JIF }\end{array}$ & $\begin{array}{r}=1.344 \\
=0.829 \\
=0.564 \\
=1.500\end{array}$ & $\begin{array}{l}\text { SIS (USA) } \\
\text { PИНЦ (Russia } \\
\text { ESJI (KZ) } \\
\text { SJIF (Moroccc }\end{array}$ & $\begin{array}{l}=0.912 \\
=0.234 \\
=1.042 \\
=\mathbf{2 . 0 3 1}\end{array}$ & $\begin{array}{l}\text { ICV (Poland) } \\
\text { PIF (India) } \\
\text { IBI (India) }\end{array}$ & $\begin{array}{l}=6.630 \\
=1.940 \\
=4.260\end{array}$ \\
\hline
\end{tabular}

технологического процесса представлены на рисунке 6. Наибольшая прочность проката с различным содержанием алмазного наполнителя достигается за два цикла МТО, что хорошо согласуются с данными, представленными на рисунке 4. Уменьшение пористости в процессе МТО существенно повышает прочность проката.

Материал с содержанием 0,8 масс. \% наполнителя имеет наибольшие механические свойства, что связано с большой вероятностью образования металлической связи между частицами меди в процессе спекания и МТО [8].

Значения микротвердости материала с содержанием наполнителя 0,8 масс. \% также достигают максимума после двух циклов МТО (рисунок 7). Значение микротвердости составляет 600 МПа, что несколько ниже микротвердости порошкового проката из меди.

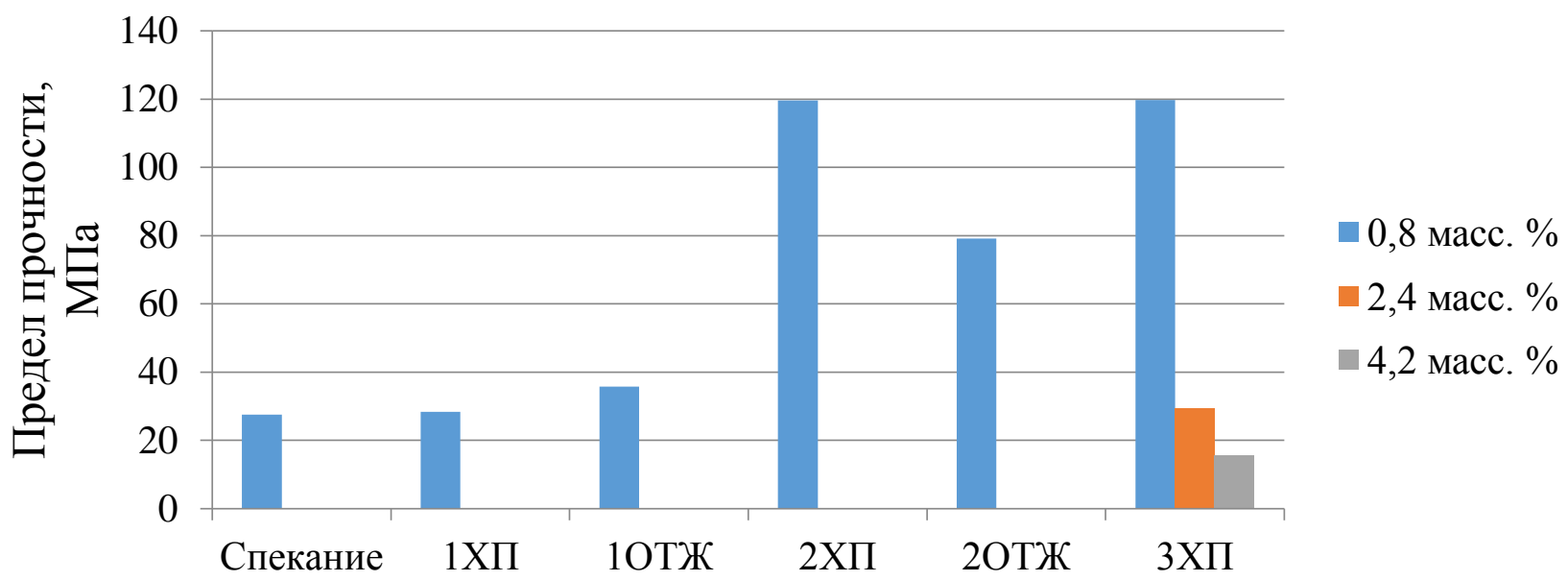

Рисунок 6 - Диаграмма изменения предела прочности на растяжение по операциям технологического процесса

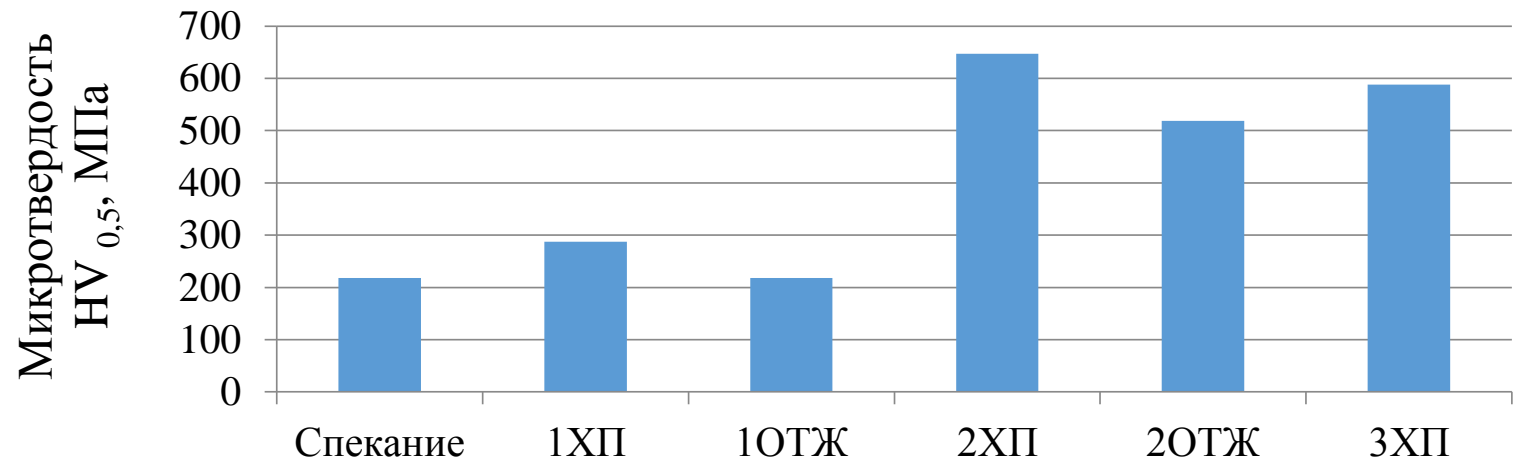

Рисунок 7 - Диаграмма изменения микротвердости материала с концентрацией наполнителя 0,8 масс. \% по операциям технологического процесса

Микроструктура полученных материалов

Микроструктура материала с концентрацией алмазного наполнителя 0,8 масс. \% по операциям технологического процесса представлена на рисунке 8. Микроструктура материала свидетельствуют о равномерном распределении наноалмазного наполнителя по границам частиц порошка меди.
Полученные относительно низкие механические свойства связаны с влиянием алмазного наполнителя. В работе [8] показано, что расчетное предельное значение условной концентрации $K$ наполнителя было значительно превышено. 


\begin{tabular}{|c|c|c|c|c|c|c|}
\hline Impact Factor: & $\begin{array}{l}\text { ISRA (India) } \\
\text { ISI (Dubai, UAF } \\
\text { GIF (Australia) } \\
\text { JIF }\end{array}$ & $\begin{array}{l}=1.344 \\
=0.829 \\
=0.564 \\
=1.500\end{array}$ & $\begin{array}{l}\text { SIS (USA) } \\
\text { PИНЦ (Russia) } \\
\text { ESJI (KZ) } \\
\text { SJIF (Morocco) }\end{array}$ & $\begin{array}{l}=0.912 \\
=0.234 \\
=1.042 \\
=\mathbf{2 . 0 3 1}\end{array}$ & $\begin{array}{l}\text { ICV (Poland) } \\
\text { PIF (India) } \\
\text { IBI (India) }\end{array}$ & $\begin{array}{l}=6.630 \\
=1.940 \\
=4.260\end{array}$ \\
\hline
\end{tabular}

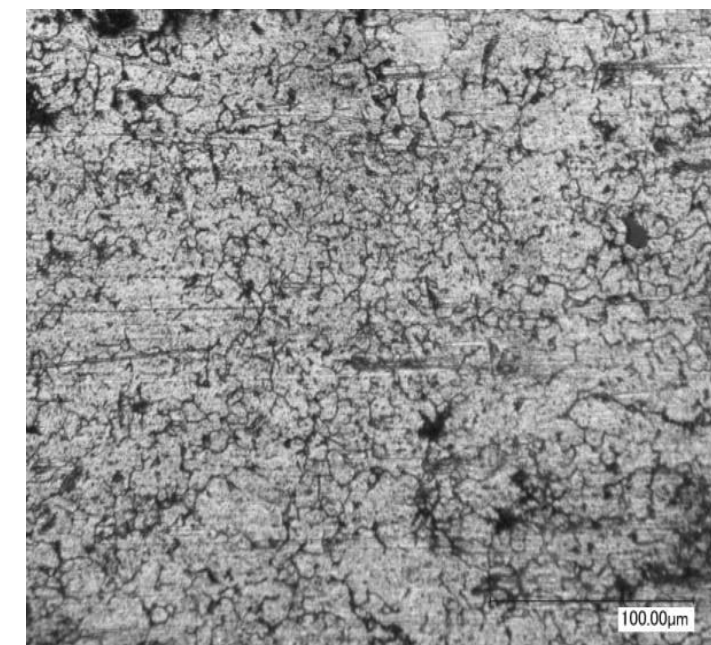

a

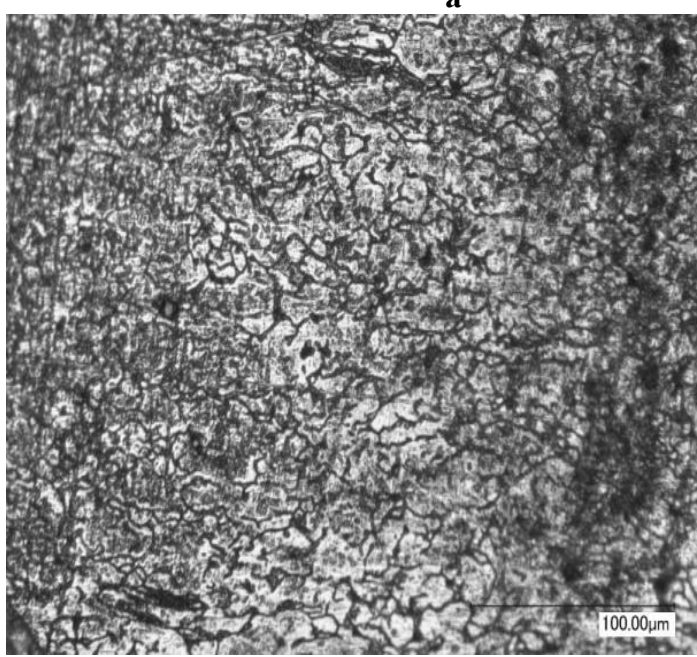

B

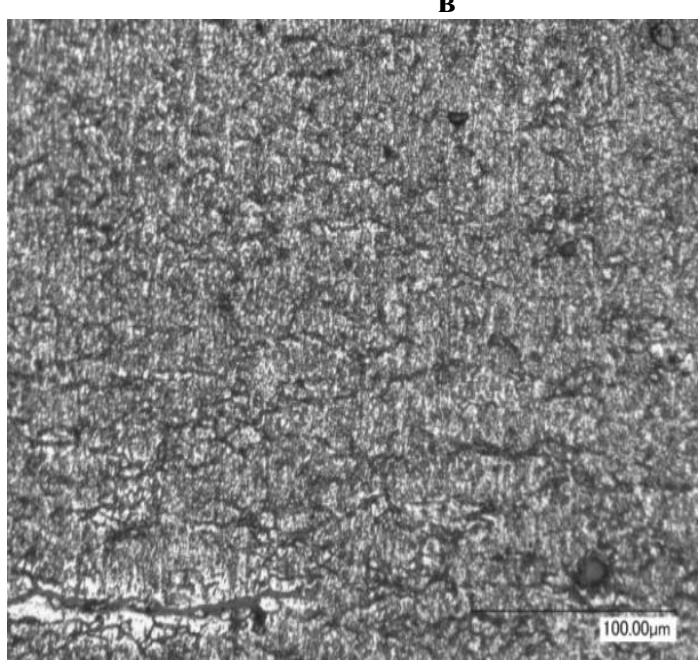

д

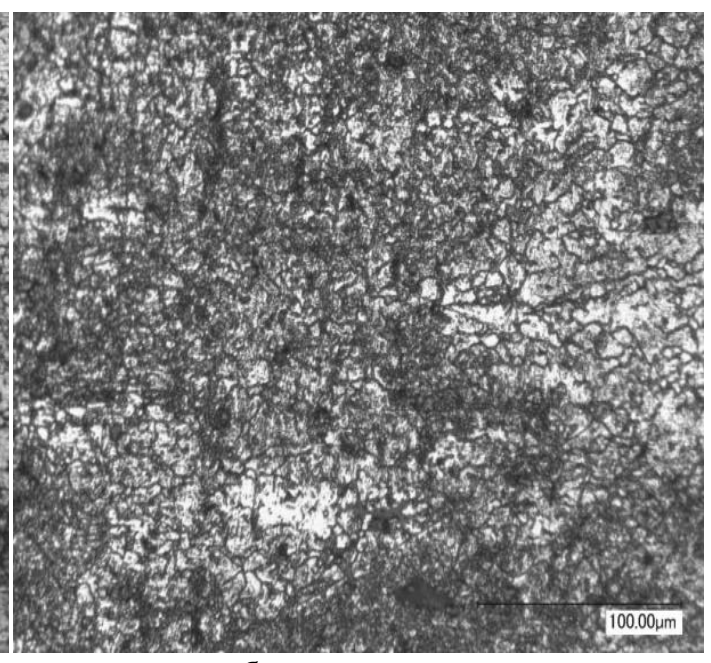

б

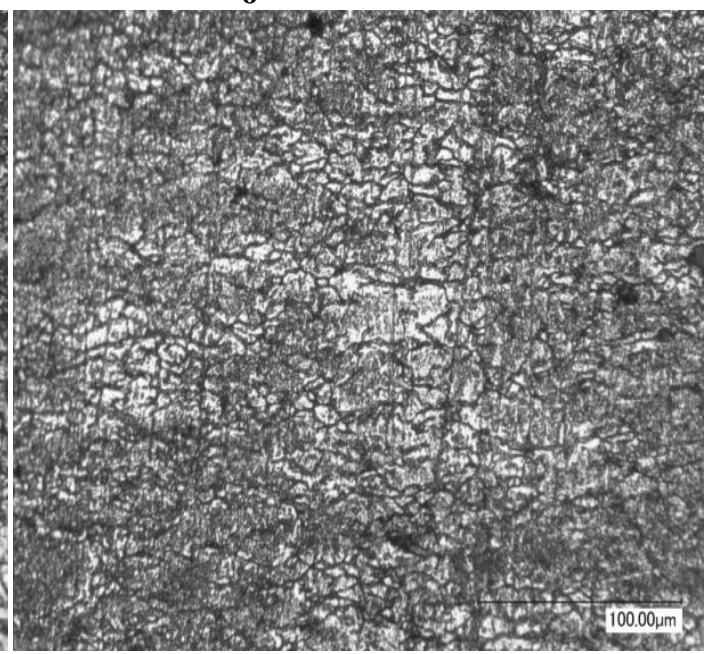

$\Gamma$

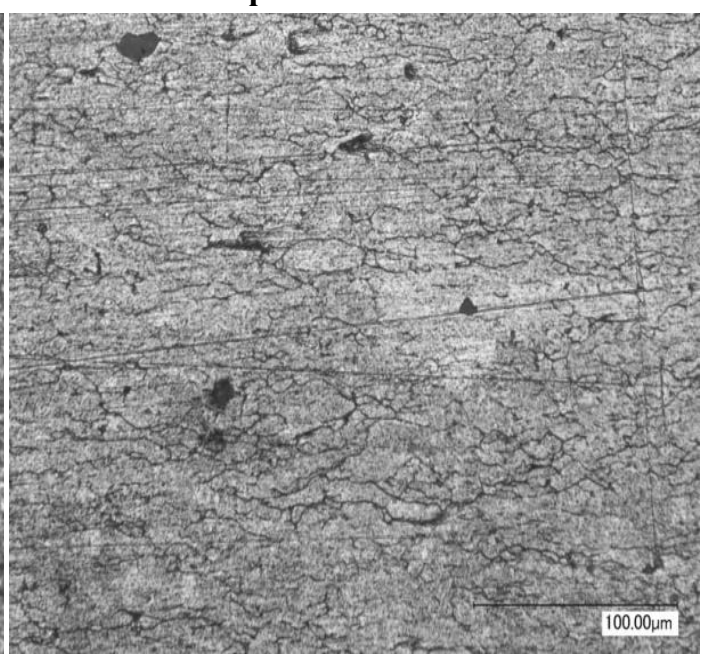

e

Рисунок 8 - Микроструктура образцов при увеличении х1000: а - спекание, б - ХП1, в - отжиг 1, г ХП2, д - отжиг 2, е - ХП3.

Согласно [8] вероятность образования металлической связи между частицами порошка меди при концентрации алмазного наполнителя 2,4 масс. \% и 4,2 масс. \% весьма мала. Однако, получение весьма низких физико-механических свойств при концентрации наполнителя 2,4 масс. $\%$ и 4,2 масс. \% объясняется наличием металлической связи в небольшом объеме материала. В процессе уплотняющей прокатки нарушается сплошность слоя наноалмазов под
ISPC Technological breakthrough in science, Philadelphia, USA 
давлением, вследствие чего и образовывалась металлическая связь.

\section{Выводы}

Была разработана технология получения проката с нанометрическим неабразивным алмазным наполнителем на основе порошка меди.

Максимальное уплотнение данного материала достигается за два цикла механикотермической обработки.

C ростом концентрации наноалмазного наполнителя пористость повышается, т.к. наполнитель препятствуют образованию металлической связи и тем самым усложняют компактирование материала.

Резкое снижение предела прочности у образцов с концентрацией наноалмазов 2,4\% и
4,2\% по сравнению с образцом с концентрацией наноалмазов $0,8 \%$ объясняется изолирующим действием наноалмазного наполнителя при термической обработке.

В результате получена агрегатная структура дисперсноупрочненого материала [10] и соответствующий эффект каркасного разупрочнения. Для получения дисперсной структуры необходимо применение помола в высокоэнергетических мельницах или проведение спекания с присутствием жидкой фазы.

Значения микротвердости у проката с наноразмерным алмазным наполнителем соизмеримы с твердостью порошкового проката из меди.

\section{References:}

1. (2011) Tekhnologiya izgotovleniya i oborudovaniye po proizvodstvu poroshkovykh i kompozitsionnykh materialov i izdeliy: ucheb. posobiye / V.K. Sorokin, L.S. Shmelev - NGTU im. R.Ye. Alekseyeva. Nizhniy Novgorod, 2011. - 184 p.

2. (2002) Proizvodstvo poroshkovogo prokata / Pod red. V. K. Sorokina. - M.: ZAO «Metallurgizdat», 2002. - 296 p.

3. Sorokin VK (2001) Osobennosti almazosoderzhashchikh smesey poroshkov i spechennykh plastin / V. K. Sorokin, L. S. Shmelev // Metallurgiya. - 2001. - № 11. - p. 53-54.

4. Kolosova TM (2013) Almazosoderzhashchiye materialy dlya otreznogo instrumenta na osnove zheleznogo poroshka /T.M. Kolosova, V.K. Sorokin, S.V. Kostromin, Belyayev E.S // Sovremennyye problemy nauki i obrazovaniya. - 2013. — , №. 2. - p. 209-217.

5. Khlybov AA (2015) Razvitiye nauchnogo napravleniya po almazosoderzhashchim poroshkovym materialam / Khlybov A.A., Sorokin V.K., Kolosova T.M., Belyayev E.S. // V sbornike: Mezhdistsiplinarnyye podkhody $\mathrm{V}$ materialovedenii i tekhnologii. Teoriya i praktika. Sbornik trudov Vserossiyskogo soveshchaniya zaveduyushchikh kafedrami materialovedeniya i tekhnologii materialov.
Belgorodskiy

gosudarstvennyy tekhnologicheskiy universitet im. V.G. Shukhova. 2015. p. 250-255.

6. Gavrilov GN (2008) Almazno-abrazivnyye materialy dlya otreznykh krugov razdeleniya $\mathrm{v}$ mikroelektronike / Gavrilov G.N., Sorokin V.K., Kolosova T.M. // Radiopromyshlennost'. 2008. № 2. p. 145-149.

7. Gavrilov GN (2007) Proizvodstvo zagotovok instrumentov dlya almazno-abrazivnoy rezki / Gavrilov G.N., Sorokin V.K., Kolosova T.M. // Zagotovitel'nyye proizvodstva V mashinostroyenii. 2007. № 7. p. 53-55.

8. Belyaev ES, Sorokin VK, Makarov NV, Kravchenko MA (2017) THE INFLUENCE OF MICRO - AND NANO-SIZED DIAMOND FILLERS ON POWDER ROLLING PHYSICAL AND MECHANICAL PROPERTIES. ISJ Theoretical \& Applied Science, 02 (46): 155-162.

9. R. German (2009) Poroshkovaya metallurgiya ot A do YA. Per. s angl.: Uchebnospravochnoye rukovodstvo / R. German Dolgoprudnyy: Izdatel'skiy dom «Intellekt», 2009. - $336 \mathrm{~s}$.

10. Libensov GA (1990) Proizvodstvo poroshkovykh izdeliy - M.:Izdatel'stvo «Metallurgiya», 1990.- 237 p. 